\title{
Clear consensus among international public for government action at COP26: Patriotic and public health frames produce marginal gains in support
}

\section{Tessa Buchanan}

University of Cambridge

James Ackland

University of Cambridge

Sam Lloyd

University of Cambridge

Sander van der Linden

University of Cambridge

Lee de-Wit ( $\nabla$ lhd26@cam.ac.uk)

University of Cambridge https://orcid.org/0000-0003-3048-2875

\section{Research Article}

Keywords: Climate Change Conference (COP26), protecting wildlife, planting trees, Moral Foundation of Loyalty

Posted Date: October 19th, 2021

DOI: https://doi.org/10.21203/rs.3.rs-921718/v1

License: (1) This work is licensed under a Creative Commons Attribution 4.0 International License.

Read Full License

Version of Record: A version of this preprint was published at Climatic Change on February 1st, 2022. See the published version at https://doi.org/10.1007/s10584-021-03262-2. 


\section{Abstract}

This work surveys over 14,000 respondents in seven countries to assess support for government action to protect the environment, and for different policies at the 2021 UN Climate Change Conference (COP26) in Glasgow. Baseline results reveal overwhelming support for action. At least nine out of ten respondents in six countries, and $79 \%$ in the USA, agree that all governments should do more. In each country, at least $50 \%$ of respondents express support for four policies: protecting wildlife; planting trees; spending more on clean technologies; and reducing the production of greenhouse gases over thirty years. A surveyexperiment tests whether support changes when respondents are exposed to short texts framed in different ways. On average, exposure to a patriotism or public health text significantly raises support for action, albeit by only 1.6 and 1.3 percentage points respectively. On policies, exposure to either a public health text or a text based on current UN messaging increases support for tree-planting by 2.3 and 2.9 percentage points respectively. These results suggest that international public opinion is overwhelmingly in favour of government action at COP26. They highlight policies that are likely to attract majority support, and suggest that message-framing can have a very small impact.

\section{Background}

The UN Climate Change Conference (COP26) in Glasgow (November 2021) offers the first major opportunity for the world to agree more ambitious goals to tackle climate change since the Paris Agreement in 2015. There is clear scientific evidence on the need for urgent action, but for world leaders, the potential reaction of their domestic audiences will be a major consideration. International surveys show that increasing numbers of people are concerned about climate change (Fagan \& Huang, 2020). A poll of 1.2 million people conducted by the UN Development Programme and Oxford University found that $64 \%$ regarded climate change as a global emergency (The Peoples'Climate Vote / United Nations Development Programme, 2021). It found strong support for policies such as: the conservation of forests and land (54\%); the use of solar, wind and renewable power (53\%); climate-friendly farming techniques (52\%); and investing more in green businesses and jobs (50\%). A 2019 YouGov survey found that, in 28 out of 29 countries surveyed, people were more likely to say that their countries (as compared to themselves) should be doing more to tackle climate change (Smith, 2019).

Polling data can give the impression that public opinion is fixed, but there is also a rich literature highlighting that support for climate action can be influenced by message-framing (Li \& Su, 2018). In the context of climate change, a message frame can present information that remains true to the underlying science while being tailored to make the issue more understandable or feel more relevant (Nisbet, 2009).

Frames used by senior officials at the United Nations, which runs COP26, frequently reference the urgent necessity of tackling the climate emergency based on the underlying science. UN Secretary General Antonio Guterres recently described the newly-released report from the Intergovernmental Panel on Climate Change (IPCC, 2021) as a "code red for humanity". However, research suggests that 'catastrophizing' messages might not be the most effective in attracting support, particularly among 
conservative US citizens (Feinberg \& Willer, 2011). Similarly, while fear-based imagery attracts attention, it may be less effective than non-threatening material which connects to people's everyday emotions and concerns (O’Neill \& Nicholson-Cole, 2009).

One salient concern that might prove promising involves concerns about health (Maibach et al., 2010; Myers et al., 2012). Research in the US found that conservatives were likely to respond to messages framed in terms of pollution, mentioning contaminated water or forests strewn with garbage (Feinberg \& Willer, 2012). This research draws on Moral Foundation Theory (Graham et al., 2009), which argues that there are a range of different moral lenses through which people look at issues, and that understanding these moral lenses is critical to persuading them. Pollution and contamination are thought to tap into a moral concern around Purity, which is hypothesized to be rooted in an evolved sense of disgust sensitivity. The importance of Purity-focused messages in motivating pro-environmental behaviour has been demonstrated in India (Sachdeva et al., 2019).

US conservatives also react more positively to environmental messages framed in terms of the past (Baldwin \& Lammers, 2016); they are more likely than liberals to adhere to the Moral Foundation of Loyalty, which includes an element of patriotism (Graham et al 2009); and they are more receptive to messages framed in terms of benefits to their country (Wolsko et al., 2016). This parallels other work highlighting that people are more motivated to address climate change when the issue is linked to their local area (Scannell \& Gifford, 2013).

Frames based on social norms have also been successful in this context. Van der Linden et al. (2015) suggest that leveraging relevant group norms has shown promise in climate communications, while Goldberg et al. (2019) found that discussing climate change with family and friends can make a difference. A particularly important scientific norm involves the perception that most climate scientists have concluded that human-caused climate change is happening, which acts as a "gateway" to attitude change and support for public action (van der Linden et al., 2019; van der Linden et al., 2015; Zhang et al., 2018).

In the context of COP26, a limitation to the framing literature is that studies are often conducted in a single country, mainly the USA, and some results are based on relatively small samples with varied recruitment strategies. Studies rarely directly compare a range of different framings. Given the potential cultural limitations to particular framings, it is therefore theoretically and practically important to understand how different message framings might impact support for climate action around the world.

This current study combines a large-scale international opinion survey with a message-framing experiment to both assess levels of support for action and for policies at COP26, and to test whether that support is influenced by how the topic is framed. Opinion is surveyed in seven countries: the UK as COP26 host, and Brazil, China, India, Indonesia, Poland and the USA. Four popular message framings are evaluated (current UN messaging, public health, patriotism and social norms) against a fifth control condition. 


\section{Methods}

\section{Sample:}

Polling took place in December 2020. Samples of approximately 2,000 participants per country were sourced by the polling agency YouGov in Brazil, China, India, Indonesia, Poland, the UK and the US (total $n=14,627$, see Appendix F). YouGov's samples were nationally and politically representative in the UK, USA, and Poland. In Indonesia and Brazil, they were nationally representative. In China, the sample was representative of the online community, and in India, it was representative of the urban community.

\section{Design and procedure}

In each country, the sample was split randomly into five groups. Each group was presented with one of five texts and then answered two questions.

Firstly respondents were asked: "Do you agree or disagree that all national governments should do more to protect the environment?" This question was worded to reflect the dynamics facing leaders at COP26, when governments will be taking decisions collectively. It was also designed to allow participants to express support for environmental action without implicitly criticising their own government.

They were then asked: "At an international meeting in November next year, governments will be asked to make commitments to protect the environment. Which of the following commitments, if any, do you think they should support":

- To protect and preserve wildlife, marine life and plants

- To plant more trees to absorb the gases that cause climate change

- To spend more on developing clean technologies

- To reduce the production over thirty years of the gases that cause climate change

- To make businesses pay for the damage they do when their activities contribute to climate change

- To give businesses a fair timetable to stop activities that contribute to climate change

- None of these, governments are already doing all they should

The policy options were framed in simple, non-scientific language, and reflected policies that governments were likely to be asked to adopt at COP26, or that could be significant in compelling businesses to accept the need for change (for complete texts, see Appendix A).

\section{Stimuli}

The between-subject design presented participants with one of five different texts (for full texts, see Appendix C). The texts were of roughly equal length (230-250 words), and were based around a common framework (see Appendix B). This began with an expression that was easy to agree with; asked people to recall a personal experience; mentioned fires, floods, storms, animals, birds and trees; referred to scientists; suggested climate change is a solvable problem; and ended with a call to action. 
The neutral text was used to establish baseline levels of support. This included the first four elements above, but was drafted in a manner designed to obscure their relation to climate change ("Consider the thinking that goes into the creation of an artwork showing dramatic scenes of fire, floods or storms").

The "Current UN Messaging" text can be considered as an 'active control' in that it draws on the language and themes of recent speeches by the UN Secretary General Antonio Guterres, reflecting the UN's current climate change messaging. This text emphasized the science around climate change ("greenhouse gas concentrations are at the highest levels in 3 million years"), and stressed that: "We have no time to lose if we are to avert climate catastrophe. This is a pivotal year for how we address the climate emergency".

The "Public Health" text focused on the need to tackle climate change to reduce pollution - a highly salient issue in many of these countries. It stressed that "health is wealth" and emphasised the contaminating and violating potential of climate change. It noted that, with air pollution, "some particles are so small they can pass through the lungs into the bloodstream", and that floods can swamp homes with "filthy, disease-ridden sewage".

The "Social Norms" text included a reference to international social norms from Ipsos Mori (in a recent international survey, a large majority $(65 \%)$ think governments should prioritise environmental measures in the years ahead"). It mentioned the 'Gateway belief' on the scientific consensus that human-caused climate change is underway, then gave a local norm for those who agreed in that country. The inclusion of genuine polling figures (which ranged from 69-88\%), taken from a 2020 YouGov poll, meant the texts were not $100 \%$ comparable, but they demonstrated that large majorities in each country believed in human-caused climate change.

The "Patriotism" text was also tailored for each country. In each text, there were three mentions of the country or nationality, including a reference to a local species identified by the World Wildlife Fund as being at risk from climate change (e.g. "China's giant pandas"). It primed a longer-term perspective ("Our country was built by generation upon generation who worked hard to ensure their children had a better life than they did"). It mentioned the forces of law and order ("Our soldiers, firemen and national services have fought bravely against wildfires and floods") and told participants that: "We have a duty to protect and preserve this land. When the time comes, we will want to tell our children that we played our part in conserving their natural heritage".

\section{Results}

In the neutral condition, in six countries, at least $90 \%$ of respondents either agreed, strongly agreed, or very strongly agreed that all governments should do more to protect the environment. In the UK, this figure was 90.0\% [95\% Cl:89.5-90.5], in Brazil, it was 97.5\% [95\% Cl:97.3-97.8], China 91.6\% [95\%Cl:91.1-92.0], India 92.3\% [95\% Cl: 91.9-92.8], Indonesia 98.9\% [95\%Cl:98.7-99.0] and Poland 90.5\% [95\%Cl:90.0-90.9]. In the USA, the figure was 79.1\% [95\% Cl:78.4-79.7] (for graphs see Appendix I). 
There was strong support in the seven countries for policy action. In the neutral condition, at least $50 \%$ of participants in each of the seven countries agreed on four policies: Protecting wildlife (across countries, this ranged from 66.0-84.2\%); planting trees (62.8-81.4\%); spending more on clean technologies (54.1$78.2 \%$; and reducing the production of greenhouse gases over thirty years (50.0-68.4\%). In all countries except China, where support was $47.6 \%$, making businesses pay for climatic damage (47.6-70.3\%) was a more popular option than giving them a fair timetable to end anti-environmental activity (40.6-55.0\%).

\section{Message-framing results:}

Only significant message-framing effects are reported here, full results and the analytical strategy are reported in Appendices D-H.

Support for government action: Compared to the baseline, exposure to one of the climate change texts led to a small rise in support for government-led action (Kruskal-Wallis $X^{2}(4,14622)=13.66, p=.008, \eta^{2}=$ 0.001 [95\% Cl:0.000-0.002]). Follow-up comparison Wilcoxon rank sum tests (with a Holm-Bonferronicorrection) showed that, compared to the neutral condition, there was a very small increase in support for participants exposed to the "Public Health" ( $W=4135367, p=0.009, d=0.07$ [95\%Cl:0.02-0.13]), "Patriotism" ( $W=4180116, p=0.009, d=0.07$ [95\%Cl:0.02-0.12]) and "Current UN Messaging" ( $W=$ $4274599, p=0.024, d=0.05$ [95\% Cl:0.00-0.10]) texts. There was no discernible increase in support for participants in the "Social Norms" condition ( $W=4240307, p=0.181, d=-0.00$ [95\%Cl:-0.05-0.05])

Support for policies: Using a Holm-Bonferroni-corrected logistic regression model across message and country (see Appendix $\mathrm{H}$ ), the "Current UN messaging" text resulted in a 2.9 percentage point increase in support for tree-planting (logit $B=.16, \mathrm{p}=.034, \mathrm{OR}=1.18[95 \% \mathrm{Cl}: 1.05,1.32]$ ), and the "Public Health" text resulted in a 2.3 percentage point increase in support for tree-planting (logit $B=.16, \mathrm{p}=.034, \mathrm{OR}=1.17$ [95\%Cl:1.04, 1.32]). No other message effects were robustly significant when correcting for multiple comparisons.

\section{Discussion}

This sample showed an overwhelming consensus in favour of further government-led action. The baseline figures are consistent with other large-scale polling ahead of COP26, which has shown a steady rise in concern about environmental issues. While support in the USA was lower than elsewhere, it was still the case that over three-quarters of the population supported further government action. A political breakdown of the results from the US showed 95.0\% [95\%Cl:94.6-95.4] of those who voted for Joe Biden as US President in 2020 were in favour, but even a majority $54.9 \%$ [95\% Cl:54.0-55.7] of respondents who voted for Donald Trump agreed.

With baseline levels of support already at such high levels, this left a very narrow window in which any message-framing might demonstrate its effectiveness. There were, however, very small increases in support for government-led action among those exposed to the "Public Health", "Patriotism" and "Current UN Messaging" conditions. These effects equated to one or two percentage points, or a Cohen's d of 
between $0.05-0.07$. This was a very short intervention, and it is plausible that more might be achieved if such frames were used as part of a more sustained, or multimedia campaign (Goldberg et al., 2019, 2021).

In terms of baseline support for policies that might be adopted at COP26, there was majority support for at least four. Support for tree-planting rose when respondents were exposed to the "Current UN messaging" or "Public Health" texts. While it is unclear why these texts in particular were successful, it is notable that tree-planting was already the second most popular policy in the baseline condition (exceeded only by 'protecting wildlife'). For businesses, the strong public support for making them pay for environmental damage may be an argument that tilts the balance in favour of agreeing a fair timetable to adapt.

Whilst the interaction between country and frame was not significant for either outcome, the overall effects of the intervention were so small that it is not possible to be confident whether the different frames would work equally well in all countries (see Appendix I). A longer intervention, larger samples per condition or a less skewed distribution (in Q1) might show up stronger effects that could bring to light differences across countries.

In summary, this study shows that international public opinion is overwhelmingly in favour of all governments doing more to protect the environment. For those publics that remain unconvinced, this study suggests that marginal gains in support could be obtained by exploring different message frames. There is also room for leadership at COP26 in translating overwhelming support for government action into support for particular policy outcomes.

\section{Declarations}

Funding - ESRC Impact acceleration fund

Data availability - On OSF, link in appendix

Materials availability - Full survey in appendix

Code availability - on OSF link in appendix

Authors' contributions - in appendix, currently blinded for review

Declarations (ethics):

- Conflict of Interest / Competing interests - none

- Additional declarations for articles that report the results of studies involving humans and/or animals:

- Ethics approval (include appropriate approvals or waivers) - approval confirmed in appendix

- Consent to participate (include appropriate statements) - consent statement in appendix (preamble) 
- Consent for publication (include appropriate statements) - consent statement in appendix (preamble)

\section{References}

Baldwin, M., \& Lammers, J. (2016). Past-focused environmental comparisons promote proenvironmental outcomes for conservatives. Proceedings of the National Academy of Sciences, 113(52), 14953-14957. https://doi.org/10.1073/pnas.1610834113

Fagan, M., \& Huang, C. (2020). Many globally are as concerned about climate change as about the spread of infectious diseases. Pew Research Center. https://www.pewresearch.org/facttank/2020/10/16/many-globally-are-as-concerned-about-climate-change-as-about-the-spread-ofinfectious-diseases/

Feinberg \& Willer. (2012). The Moral Roots of Environmental Attitudes -. https://journals.sagepub.com/doi/10.1177/0956797612449177

Feinberg, M., \& Willer, R. (2011). Apocalypse Soon?: Dire Messages Reduce Belief in Global Warming by Contradicting Just-World Beliefs. Psychological Science, 22(1), 34-38. https://doi.org/10.1177/0956797610391911

Goldberg, M. H., Gustafson, A., Rosenthal, S. A., \& Leiserowitz, A. (2021). Shifting Republican views on climate change through targeted advertising. Nature Climate Change, 11(7), 573-577. https://doi.org/10.1038/s41558-021-01070-1

Goldberg, M. H., Linden, S. van der, Maibach, E., \& Leiserowitz, A. (2019). Discussing global warming leads to greater acceptance of climate science. Proceedings of the National Academy of Sciences, 116(30), 14804-14805. https://doi.org/10.1073/pnas.1906589116

Goldberg, M. H., van der Linden, S., Ballew, M. T., Rosenthal, S. A., Gustafson, A., \& Leiserowitz, A. (2019). The Experience of Consensus: Video as an Effective Medium to Communicate Scientific Agreement on Climate Change. Science Communication, 41(5), 659-673. https://doi.org/10.1177/1075547019874361

Graham, J., Haidt, J., \& Nosek, B. A. (2009). Liberals and conservatives rely on different sets of moral foundations. Journal of Personality and Social Psychology, 96(5), 1029-1046.

https://doi.org/10.1037/a0015141

Li, N., \& Su, L. Y.-F. (2018). Message Framing and Climate Change Communication: A Meta-Analytical Review. Journal of Applied Communications, 102(3), 1c-1c. https://doi.org/10.4148/1051-0834.2189

Maibach, E. W., Nisbet, M., Baldwin, P., Akerlof, K., \& Diao, G. (2010). Reframing climate change as a public health issue: An exploratory study of public reactions. BMC Public Health, 10(1), 299.

https://doi.org/10.1186/1471-2458-10-299 
Myers, T. A., Nisbet, M. C., Maibach, E. W., \& Leiserowitz, A. A. (2012). A public health frame arouses hopeful emotions about climate change. Climatic Change, 113(3), 1105-1112.

https://doi.org/10.1007/s10584-012-0513-6

Nisbet, M. C. (2009). Communicating Climate Change: Why Frames Matter for Public Engagement. Environment: Science and Policy for Sustainable Development, 51(2), 12-23.

https://doi.org/10.3200/ENVT.51.2.12-23

O’Neill, S., \& Nicholson-Cole, S. (2009). "Fear Won't Do It": Promoting Positive Engagement With Climate Change Through Visual and Iconic Representations. Science Communication, 30(3), 355-379. https://doi.org/10.1177/1075547008329201

Sachdeva, S., Boghrati, R., \& Dehghani, M. (2019). Testing the Influence of Purity-Based Interventions on Pro-environmental Behavior. Sustainability, 11(6), 1811. https://doi.org/10.3390/su11061811

Scannell, L., \& Gifford, R. (2013). Personally Relevant Climate Change: The Role of Place Attachment and Local Versus Global Message Framing in Engagement. Environment and Behavior, 45(1), 60-85. https://doi.org/10.1177/0013916511421196

Smith, M. (2019). International poll: Most expect to feel impact of climate change, many think it will make us extinct. YouGov. https://yougov.co.uk/topics/science/articles-reports/2019/09/15/international-pollmost-expect-feel-impact-climate

The Peoples' Climate Vote | United Nations Development Programme. (n.d.). Retrieved September 6, 2021, from https://www.undp.org/publications/peoples-climate-vote

van der Linden, S. L., Leiserowitz, A. A., Feinberg, G. D., \& Maibach, E. W. (2015). The scientific consensus on climate change as a gateway belief: Experimental evidence. PloS One, 10(2), e0118489. https://doi.org/10.1371/journal.pone.0118489

van der Linden, S., Leiserowitz, A., \& Maibach, E. (2019). The gateway belief model: A large-scale replication. Journal of Environmental Psychology, 62, 49-58.

https://doi.org/10.1016/j.jenvp.2019.01.009

van der Linden, S., Maibach, E., \& Leiserowitz, A. (2015). Improving Public Engagement With Climate Change: Five "Best Practice" Insights From Psychological Science. Perspectives on Psychological Science: A Journal of the Association for Psychological Science, 10(6), 758-763. https://doi.org/10.1177/1745691615598516

Wolsko, C., Ariceaga, H., \& Seiden, J. (2016). Red, white, and blue enough to be green: Effects of moral framing on climate change attitudes and conservation behaviors. Journal of Experimental Social Psychology, 65, 7-19. https://doi.org/10.1016/j.jesp.2016.02.005 
Zhang, B., van der Linden, S., Mildenberger, M., Marlon, J. R., Howe, P. D., \& Leiserowitz, A. (2018).

Experimental effects of climate messages vary geographically. Nature Climate Change, 8(5), 370-374. https://doi.org/10.1038/s41558-018-0122-0

\section{Supplementary Files}

This is a list of supplementary files associated with this preprint. Click to download.

- SupplementaryforClimateFraming.docx 